\title{
NOTAS SOBRE AS PARTICULARIDADES POLÍTICAS DO GOVERNO LULA
}

\author{
Maria Angélica Paraizo ${ }^{1}$
}

\begin{abstract}
RESUMO: O presente artigo apresenta a discussão sobre como o atendimento de interesses seletivos das classes trabalhadoras foi funcional para o projeto neodesenvolvimentista do governo Lula, sendo esses interesses compatíveis com os interesses fundamentais das frações burguesas favorecidas por esse governo. Deste modo, busca-se expor as particularidades do cumprimento da função geral do Estado capitalista pelo governo Lula. Neste debate, intenta-se, ainda, demonstrar como as classes populares tornaram-se apoio do neodesenvolvimentismo petista por intermédio de uma ilusão ideológica com fundamentos materiais, resultando em uma relação do tipo populista desses setores sociais com o governo em questão.
\end{abstract}

PALAVRAS-CHAVE: Governo Lula; Classes Dominadas; Classes Dominantes; Neodesenvolvimentismo; Populismo.

\section{REMARKS UPON THE POLITICAL PARTICULARITIES OF LULA GOVERNMENT}

\begin{abstract}
This paper aims to show the discussion about how the selective interests of the working classes served the Lula government neodevelopmentalist project in a manner compatible with the fundamental interests of the bourgeois fractions. Thus, it is sought to expose the particularities of the fulfillment of the general function of the capitalist State by the Lula government. According to this, it is demonstrated how the popular classes became support of the neodevelopmentalism through an ideological illusion with

\footnotetext{
${ }^{1}$ Doutoranda no Programa de Pós-Graduação em Ciência Política da Universidade Estadual de Campinas. E-mail: angelica.paraizo@yahoo.com.br
} 
material foundations, resulting in a populist-type relationship of these social sectors with the government.

KEYWORDS: Lula government; Dominated classes; Dominant classes; Neodevelopmentalism; Populism.

\section{INTRODUÇÃO}

O presente artigo é parte da dissertação de mestrado, intitulada Populismo e o projeto de desenvolvimento do governo Lula ${ }^{2}$, que consistiu na realização de uma leitura crítica sobre as diferentes interpretações a respeito das políticas implementadas para as classes dominantes e para as classes dominadas pelo referido governo. $\mathrm{O}$ intuito dessa pesquisa foi examinar como o atendimento de interesses seletivos das classes trabalhadoras foi funcional para o projeto de desenvolvimento do governo Lula, sendo esses interesses limitados à manutenção dos interesses fundamentais das classes burguesas. O recorte temporal da análise empreendida se refere aos dois mandatos de Luís Inácio Lula da Silva (2003-2006 e 2007-2010), o que possibilitou averiguar o delineamento e a concretização da relação estabelecida por esse governo com as classes sociais brasileiras. Assim, notou-se que, durante o período considerado, houve a manutenção do modelo capitalista neoliberal periférico, porém, com mudanças na política econômica e social do país. A síntese aqui apresentada busca apenas problematizar e expor as particularidades do cumprimento da função geral do Estado capitalista pelo governo Lula. Intenta-se, ainda, demonstrar como as classes populares se relacionaram com o projeto neodesenvolvimentista que estava em curso por intermédio de uma ilusão ideológica com fundamentos materiais, resultando em uma relação do tipo populista destes setores sociais com o governo.

Deste modo, o primeiro tópico do presente artigo se concentra na apresentação de elementos da teorização poulantziana sobre a relação existente entre o Estado de tipo capitalista e as classes sociais, uma vez

\footnotetext{
${ }^{2}$ PARAIZO, M.A. Populismo e o projeto de desenvolvimento do governo Lula. Dissertação (Mestrado em Ciências Sociais) - Faculdade de Filosofia e Ciências, Universidade Estadual Paulista (UNESP). Marília, p. 117. 2017.
} 
que esse aporte teórico embasa a análise aqui realizada. Em sequência, expõe-se, por meio de dados e informações sobre as políticas sociais e econômicas do governo Lula, de que maneira o atendimento de certos interesses imediatos das classes dominadas foi funcional e compatível com os interesses econômicos e políticos da grande burguesia interna, a exemplo do aquecimento do mercado interno por meio do aumento da renda dos setores populares, da lucratividade que a construção de habitações populares gerou para as grandes construtoras e para o setor imobiliário brasileiro, etc. Com base nesses elementos, propõe-se, então, a discussão sobre como as classes populares beneficiadas pelas políticas sociais e econômicas do governo Lula, sobretudo os setores favorecidos pelas políticas de transferência direta de renda como o Bolsa Família, se tornaram classe-apoio do projeto neosenvolvimentista em vigor.

\section{O ESTADO CAPITALISTA E OS INTERESSES DE CLASSE}

Antes de adentrar ao tema específico desse artigo, é necessário realizar uma breve observação a respeito dos conceitos teóricos que embasaram as análises aqui expostas. A importância dessa digressão inicial reside no fato de que o pano de fundo do tema abordado consiste na relação existente entre as classes sociais e o tipo capitalista de Estado.

Nicos Poulantzas (1977) aponta que o Estado capitalista possui direção hegemônica de classe ao concentrar o poder político das classes dominantes, uma vez que é o fator de organização da luta política e do poder político dessas classes. Entretanto, essa forma de Estado comporta, em seu interior, um jogo que possibilita que certos interesses econômicos de certas classes dominadas sejam atendidos, mesmo que esses últimos sejam eventualmente contraditórios com os interesses econômicos de curto prazo das classes dominantes, contudo, correspondentes à manutenção de seus interesses e de sua hegemonia política. Para o cientista político grego, isso ocorre em determinada conjuntura em que o desenrolar da luta política das classes dominadas apresenta a possibilidade de confrontar o poder político das classes dominantes. 
Nesta lógica, o atendimento de certos interesses econômicos das classes dominadas produz um efeito ideológico segundo o qual o Estado capitalista se mostra como representante geral dos interesses do povo. Esse efeito é proporcionado pela autonomia específica existente nas formações sociais capitalistas entre os interesses políticos e os interesses econômicos de classe. Contudo, esta característica particular do Estado capitalista - a saber, o fato de representar o interesse geral do povo de maneira abstrata - não pode ser reduzida a uma "mistificação enganadora", pois o Estado tem a possibilidade de satisfazer concretamente os interesses econômicos das classes dominadas. Além do mais, destaca-se nesse processo a impossibilidade de conceber o Estado como um mero instrumento nas mãos das classes dominantes, uma vez que a garantia de interesses econômicos às frações das classes dominadas é impelida pela luta política e econômica destas classes, mesmo que de maneira circunscrita aos limites impostos pela direção hegemônica do Estado capitalista (POULANTZAS, 1977, pp. 185-188).

O sociólogo norte-americano Erik O. Wright (1981) aponta a distinção entre interesses fundamentais e interesses imediatos de classe, formulação que auxilia no entendimento da questão apontada acima. De acordo com esse autor, a conceituação de interesses de classe corresponde aos interesses fundamentais de determinada classe, a saber, os interesses potenciais dos agentes de classe. Assim, o interesse fundamental da classe capitalista, no nível político e ideológico, consiste em impedir que a classe trabalhadora obtenha o poder estatal e a hegemonia ideológica. Como oposto desta proposição, a classe trabalhadora tem o interesse fundamental de obter o poder estatal, bem como a hegemonia ideológica, destruindo o modelo capitalista de Estado de maneira qualitativa. Os interesses imediatos de classe se constituem em determinada estrutura de relações sociais, ou seja, são definidos de acordo com o modo de produção dominante de uma formação social. As lutas salariais ou por melhores condições de vida, por exemplo, têm seus objetivos definidos dentro da estrutura do capitalismo. Esses interesses não são falsos, mas sim incompletos. Por esta perspectiva, os interesses imediatos e os interesses fundamentais não existem separadamente, estando dialeticamente ligados. 
Assim, seria enganoso imaginar uma luta de classes unicamente em torno de interesses fundamentais, sem qualquer vinculação com os interesses imediatos. Porém, mesmo que exista uma relação dialética entre tais interesses, os interesses imediatos acabam por dividir a classe trabalhadora, repercutindo na luta contra a estrutura capitalista. Desta forma, a superação do modo de produção capitalista dependerá da convergência entre a luta por interesses imediatos e a luta por interesses fundamentais (WRIGHT, 1981, pp. 84-85).

De acordo com essas formulações teóricas, é possível destacar dois elementos sobre as lutas de classes e a garantia de certos interesses das classes dominadas no contexto do governo Lula. Primeiramente, ressalta-se que, para além do atendimento dos interesses políticos e do estabelecimento da hegemonia da grande burguesia interna no interior do bloco no poder brasileiro (BOITO JR, 2012), alguns de seus "interesses econômicos" foram igualmente contemplados, "a curto prazo", pelo favorecimento econômico das classes dominadas. Em segundo lugar, o fato de a promoção da melhora nas condições de vida das classes populares ser realizada em consonância com medidas que beneficiaram frações da burguesia brasileira não denota nenhum contrassenso, tampouco uma forma de governar absolutamente inovadora, mas sim uma postura coerente com os princípios do Estado capitalista conforme uma determinada conjuntura da luta de classes. Entretanto, é preciso ressaltar algumas particularidades conjunturais da relação estabelecida pelo governo Lula com as classes dominantes e com as classes dominadas.

\section{O GOVERNO LULA E OS INTERESSES DE CLASSE}

As políticas implementadas pelo governo Lula, com base na proposta de "crescimento com distribuição de renda", objetivavam contemplar amplos setores sociais. Essas políticas eram descritas por intelectuais governistas $^{3}$ de maneira alusiva a uma forma de simbiose entre as classes sociais: uma harmoniosa interdependência com vantagens mútuas tanto

${ }^{3}$ Como as análises de Araújo (2006) e Mercadante (2010). 
para as classes dominantes, quanto para as classes dominadas. Entretanto, essa pretensa relação simbiótica entre classes sociais antagônicas não é exequível politicamente no âmbito do Estado capitalista. Porém, é possível observar que o delineamento político e econômico do referido governo propiciou uma inter-relação entre as políticas destinadas às classes populares, por meio do atendimento de interesses imediatos dessas classes, e os interesses políticos e econômicos das frações dominantes favorecidas no período em questão, de modo a consolidar a hegemonia política da grande burguesia interna no interior do bloco no poder brasileiro.

As políticas de transferência de renda para a população mais pobre do país, a expansão de postos de trabalho, a recuperação do salário mínimo, a facilitação do crédito à pessoa física a juros baixos e o controle da inflação são exemplos de políticas realizadas pelo governo que aumentaram o padrão do consumo das classes populares. $\mathrm{O}$ aumento do consumo por parte das classes populares, consequentemente, colaborou para o aquecimento do mercado interno, o que, numa espécie de efeito em cadeia, favoreceu diversos setores industriais no país.

Dados referentes ao ano de 2010 apontam um aumento significativo nos gastos concernentes ao consumo por parte dos brasileiros: o total do consumo familiar no ano de 2002 era de $\mathrm{R} \$ 1,47$ trilhão e passou a $\mathrm{R} \$ 1,97$ trilhão no ano de 2009. Esse aumento de $\mathrm{R} \$ 50$ bilhões se concentrou, sobretudo, na participação da chamada "classe C" na aquisição de bens e serviços: no ano de 2002 a taxa de participação no consumo deste setor correspondia a 23,7\%, saltando para 31,8\% em $2009^{4}$. A classe C corresponde, na verdade, a setores das classes trabalhadoras que melhoraram suas condições de vida por meio das políticas de expansão de postos de trabalho, o que contemplou a base da pirâmide social brasileira, e do aumento gradual do salário mínimo durante o governo Lula. Isso se deve ao fato de que:

\footnotetext{
4 Da Redação. Consumo teve alta de $\mathrm{R} \$ 500$ bi na era Lula, diz estudo. Revista Exame. 10 out. 2010. Disponível em:http://exame.abril.com.br/economia/ consumotevealtader500binaeraluladizestudo540195/. Acessado em: 22 nov. 2016
} 
Em grande medida, a forte expansão do conjunto das ocupações de salário de base pertencentes ao setor terciário e da construção civil e indústria extrativa favorecen a mais rápida incorporação dos trabalhadores na base da piramide social. Com isso, uma parcela considerável da força de trabalho conseguiu superar a condição de pobreza, transitando para o nível inferior da estrutura ocupacional de baixa remuneração embora não seja mais pobre, tampouco pode ser considerada de classe média (POCHMANN, 2012, p. 2., grifos nossos).

De acordo com o excerto acima, observa-se que o aumento de postos de trabalho durante o governo de Lula da Silva ocorreu nos ramos vinculados ao setor de serviços, à construção civil e à indústria extrativa, setores que se beneficiaram das políticas de governo no período em questão. Constata-se, assim, um fenômeno de duplo caráter: o restabelecimento do compromisso do Estado brasileiro para com os grupos econômicos nativos favoreceu a expansão destes, o que consequentemente, promoveu a expansão do emprego no país. A expansão do emprego, por sua vez, colaborou para a inclusão de uma ampla gama de trabalhadores ao mercado de trabalho formal, o que resultou no aumento do consumo por parte das classes populares (consumo este amparado pelo controle inflacionário). Também se insere na lógica destacada acima o Programa Bolsa Família. Segundo Neri et al (2013), o PBF é o programa de transferência de renda que tem maior incidência sobre o PIB brasileiro ${ }^{5}$. Cada $1 \%$ do PIB investido no Bolsa Família corresponde ao aumento de 1,78\% na atividade econômica do país. Para os autores, o efeito multiplicador do Bolsa Família é maior do que o dos outros benefícios sociais por favorecer diretamente os mais pobres, parcela social mais propensa ao consumo.

Outra questão que merece destaque na inter-relação existente entre as políticas de governo para as classes dominadas e as políticas para as classes dominantes está na criação do Programa Minha Casa, Minha Vida (PMCMV), em 2009. O propósito oficial desse programa consistiu em

\footnotetext{
${ }^{5}$ Ao ser comparado com programas de transferência de renda do governo FHC e também ao Benefício de Prestação Continuada (BPC).
}

Temáticas, Campinas, 27, (53): 17-38, fev./jun. 2019 
facilitar o acesso à casa própria às famílias que necessitavam de moradia ${ }^{6}$. O PMCMV foi exitoso em seu propósito de ampliar e facilitar o acesso a moradias populares ${ }^{7}$, ao mesmo tempo em que os setores vinculados ao mercado imobiliário e à construção civil foram beneficiados sobremaneira pela política de habitação do governo.

Atrelado ao Programa de Aceleração do Crescimento (PAC), uma das justificativas para o lançamento do PMCMV foi que esse programa seria uma estratégia para enfrentar a crise de 2008 por meio da aposta em seu efeito multiplicador. O pacote habitacional é anunciado pelo governo como uma política anticíclica embasada no atendimento de interesses sociais. Seu lançamento despertou o interesse de setores econômicos vinculados à construção civil, o que estimulou o surgimento de novos arranjos empresariais diante do fortalecimento do setor financeiro alinhado ao mercado imobiliário e de grandes grupos empresariais do ramo da construção civil. Grandes construtoras, que anteriormente atendiam o setor imobiliário com padrão de alto luxo, passaram a aderir ao padrão voltado para os setores abarcados pelo PMCMV, ampliando sua presença em locais onde anteriormente predominavam empresas de pequeno e médio porte. Construtoras como a MRV e a Rossi começaram a atuar em

${ }^{6}$ O Programa Minha Casa, Minha Vida em vigor nos governos petistas previa a participação de famílias com renda de até 10 salários mínimos. Os subsídios e incentivos do governo se davam de acordo com a divisão de faixas salariais. A Faixa 1 compreendia famílias com renda de até 3 salários mínimos e contava com subsídio máximo do governo, isenção do seguro e prestações mensais limitadas a $10 \%$ da renda num financiamento de 10 anos. A Faixa 2 abarcava famílias cuja renda compreendesse entre 3 a 6 salários mínimos, contando com subsídio parcial, acesso ao Fundo Garantidor e prestações limitadas a $20 \%$ da renda num financiamento de até 30 anos. Já a Faixa 3 correspondia às famílias com renda entre 6 a 10 salários mínimos e recebiam estímulos à compra de moradias com a redução dos custos do seguro e acesso ao Fundo Garantidor. (BRASIL, 2010; ROMAGNOLI, 2012).

${ }^{7} \mathrm{O}$ PMCMV alcançou todas as metas das suas duas primeiras fases: a primeira durante os anos finais do segundo governo Lula e a segunda durante o governo de sua sucessora, Dilma Rousseff. Em março de 2015 o programa atingiu a marca de 3,857 milhões de unidades habitacionais, contabilizado as moradias já entregues às famílias que aderiram ao Programa e as demais habitações em vias de entrega no período destacado. Desde o início de 2009 contabilizou-se a liberação de R $\$ 139,6$ bilhões em financiamentos bancários ao Programa (com destaque para a Caixa Econômica Federal) e R \$ 114,9 bilhões em subsídios do governo às famílias de mais baixa renda (BRASIL, 2015).

Temáticas, Campinas, 27, (53): 17-38, fev./jun. 2019 
diversas regiões do país, a primeira em 19 dos 26 estados brasileiros e a segunda em 18 estados (OLIVEIRA, 2015).

Arantes e Fix (2009) observam que o PMCMV teve um papel importante para que as construtoras brasileiras saíssem da crise e destacam que os efeitos negativos da economia em escala global não foram os únicos motivos que tornaram o programa de habitações populares atrativo. De acordo com os autores, o setor imobiliário residencial do país passou a se recapitalizar durante os anos 2000 devido às intervenções governamentais e a sua abertura na bolsa de valores, o que culminou em sua ampliação. A junção desses fatores produziu um repentino e insustentável crescimento a longo prazo desse setor. A implementação do Programa Minha Casa, Minha Vida foi uma verdadeira salvação para a crise que se aprofundava no ramo da construção civil e no mercado imobiliário brasileiro.

No debate sobre a inter-relação das políticas destinadas às classes populares com os interesses das classes dominantes, é importante também inserir o Programa Universidade Para Todos (ProUni). Criado em 2004, o ProUni consistiu em oferecer bolsas de estudos integrais ou parciais em instituições de ensino superior de caráter privado para estudantes cuja renda bruta familiar mensal correspondesse a até um salário mínimo e meio per capita. Caracterizado pelo governo como uma política pública afirmativa, o ProUni demonstrou no decorrer dos anos resultados concretos no aumento do número de jovens cursando o ensino superior. De acordo com o Censo da Educação Superior de 2010, realizado pelo INEP/ MEC, o Brasil contava com 6,5 milhões de estudantes universitários. No acumulado da década de 2001-2010, o número de universitários no país teria mais do que dobrado, numa porcentagem de 105,05\%, com uma melhor distribuição regional desses números, abarcando as regiões Norte e Nordeste (CASALI E MATTOOS, 2015).

Ao mesmo tempo em que trouxe benefícios reais aos setores pobres da juventude brasileira, o ProUni também atendeu diretamente os interesses das instituições de ensino superior privadas. Além da ampliação da mercantilização do ensino, que resulta em ganhos diretos aos segmentos privados do campo educacional, a garantia de isenção fiscal para as instituições de ensino superior que aderissem ao programa 
favoreceu esses setores, beneficiando, principalmente, as instituições com fins lucrativos (CARVALHO, 2006). Além do mais, o ProUni serviu para contornar o número de inadimplentes existentes nas instituições de ensino superior privadas, devido à grande ampliação das vagas ofertadas por essas instituições, sobretudo durante o governo FHC (ALMEIDA, 2012). Ao promover o aumento da lucratividade das instituições privadas, em concomitância com a iniciativa de atender a grande demanda pelo acesso ao ensino superior por parte dos jovens oriundos das classes populares, o governo de Lula da Silva contemplou os interesses imediatos desta juventude pobre, atendendo, ao mesmo tempo, os interesses políticos e econômicos de setores da burguesia de serviços, figuradas, neste caso, pelo ensino superior privado.

Em relação ao Programa Bolsa Família, é necessário ressaltar dois fatores particulares. Primeiramente, destaca-se que no final da década de 90 e início dos anos 2000 havia uma urgência por soluções para o problema da fome no Brasil ${ }^{8}$. Deste modo, existia a necessidade de uma política social criativa para retirar o país do mapa mundial da fome e foi exatamente isso que o governo Lula fez com a criação do Programa Bolsa Família: um programa de transferência direta de renda com grande abrangência, segundo os critérios das organizações multilaterais. É possível afirmar, num primeiro momento, que não houve uma relação necessária entre a implementação do Programa Bolsa Família e os interesses econômicos da burguesia interna, embora a renda gerada pelo programa impactasse de maneira indireta na dinâmica do sistema produtivo brasileiro por meio do aumento do consumo desses setores sociais. O Programa Bolsa Família assume uma pertinência particular no

\footnotetext{
${ }^{8}$ No Brasil, na década de 90, a extrema pobreza e a fome crônica se mostravam como problemas que necessitavam ser superados. No ano de 1999 mais de um quarto da população brasileira $(27,4 \%)$ vivia abaixo da linha da pobreza definida pelas organizações mundiais. Deste montante, a maior parte se concentrava nas regiões Norte e Nordeste: $36,2 \%$ e 48,8\%, respectivamente, sobretudo nas áreas rurais. Projeções realizadas na época indicavam que, se nenhuma medida efetiva fosse realizada, a desnutrição infantil no país persistiria por um longo período de tempo, existindo por mais dez anos na zona urbana do Nordeste, vinte e oito anos na zona urbana da região Norte, trinta e dois anos nas áreas rurais do Centro-Sul e por um período maior que sessenta e dois anos na zona rural nordestina (MONTEIRO, 2003).
} 
que concerne aos interesses políticos da burguesia brasileira ${ }^{9}$. Como efeito da grande abrangência e do significativo impacto que essa política social teve nos setores mais pauperizados da população brasileira, originou-se uma ideologia pautada na imagem do governo enquanto benfeitor dos anseios dos mais necessitados, o que resultou em um massivo apoio por parte desses setores sociais ao projeto neodesenvolvimentista de Lula.

Pode-se observar que o governo Lula articulou de diversas maneiras interesses imediatos das classes dominadas aos interesses de frações da burguesia brasileira por meio de políticas sociais e, sobretudo, econômicas. Especialmente após o ano de 2006, o governo Lula mesclou políticas macroeconômicas de caráter neoliberal, as quais vinha seguindo em seu primeiro mandato, com medidas políticas neodesenvolvimentistas. Houve então a ação direta por parte do Estado na redução das desigualdades sociais e o amplo investimento estatal via política de fomento do BNDES aos setores industriais e a implementação das obras do PAC - destinadas principalmente a setores estratégicos infraestruturais do país. Tais elementos marcaram uma postura neodesenvolvimentista por parte desse governo (MORAIS e SAAD-FILHO, 2011, pp. 517-518).

\section{NEODESENVOLVIMENTISMO, CLASSES DOMINADAS E A PARTICULARIDADE DA POLÍTICA POPULISTA DE LULA}

$\mathrm{Na}$ conjuntura particular pré-eleição de Lula como presidente da República, identificou-se uma grande insatisfação com os rumos neoliberais extremados do governo FHC por parte da grande burguesia

\footnotetext{
${ }^{9}$ Há outras medidas implementadas pelo governo Lula - como o aprofundamento do Programa de Erradicação do Trabalho Infantil (PETI), a criação dos programas Luz para Todos, Brasil Alfabetizado e Educação de Jovens e Adultos (EJA) - que tiveram grande impacto na melhora da qualidade de vida das frações de classe mais pauperizadas do país. Contudo, a escolha por focar a discussão que realizamos em torno do PBF se justifica pela grande importância propagandística que o programa teve durante o governo Lula, tornando-se o programa social do governo petista por excelência. É inegável seu impacto no processo político do país, uma vez que durante os pleitos eleitorais presidenciais que sucederam o governo Lula, todos os presidenciáveis com significativa projeção na cena política não refutavam o programa, tampouco ameaçavam qualquer sinalização em acabar com ele.
} 
interna $^{10}$ (BOITO JR., 2018; SAES, 2001). Neste contexto, o PT - devido à postura compromissada com os interesses capitalistas que demonstrou durante a campanha eleitoral de 2002 - se tornou uma alternativa viável para a contemplação dos anseios da burguesia interna. Vale ressaltar que o vice-presidente de Lula, José Alencar, um dos ícones do empresariado brasileiro, também passou uma imagem de segurança para esses setores burgueses durante o referido pleito eleitoral (NOVELLI, 2010). Soma-se a este fato o desejo por mudanças no status quo por parte das classes populares, vitimadas pelos altos índices de desemprego, desmontes trabalhistas e corrosão salarial dos anos 90. Deste modo, a burguesia interna teve que aceitar fazer parte de uma frente com o movimento sindical e popular pelo fato de o PT ter sua origem no seio deste movimento (BOITO JR., 2012).

O neodesenvolvimentismo empenhado pelos governos do PT consistiu em um desenvolvimento possível dentro do modelo neoliberal periférico, de modo a favorecer a grande burguesia interna brasileira diante de sua contenda com a burguesia associada ao capital estrangeiro, fração burguesa que deteve a hegemonia no interior do bloco no poder durante a década de 1990 (BOITO JR., 2018). Assim, de acordo com Boito Jr. (2012, p. 68) a "frente neodesenvolvimentista" foi formada, sendo constituída pela aliança de um amplo leque de forças sociais - semiproletariado, burguesia bancária, burguesia industrial, agronegocistas, movimentos sociais - que se uniram ao governo Lula diante de seu projeto de desenvolvimento. Contudo, por reunir em seu interior frações de classes distintas, eram grandes as contradições no interior desta frente:

\footnotetext{
${ }^{10}$ De acordo com Poulantzas $(1976 ; 1977)$, a relação existente entre os países dependentes e os centros imperialistas, no contexto correspondente à internacionalização do capital, é o que possibilita a emergência dessas frações burguesas, sobretudo, da burguesia interna. A burguesia interna ocupa uma posição intermediária entre a burguesia associada e a burguesia nacional. Sua posição de meio termo é expressa, primeiramente, por seus interesses não serem totalmente subordinados ao capital estrangeiro, como no caso da burguesia associada. Em segundo lugar, pelo fato de que ela se mantém dependente do capital estrangeiro, não se posicionando contra o imperialismo, como o faria a burguesia nacional.
} 
No que diz respeito aos gastos públicos, estamos diante de um problema complexo na análise da frente neodesenvolvimentista. A grande burguesia interna reluta em aceitar as pequenas concessões que o governo Lula exige dela, para que seja possível manter a própria frente. Os grandes empresários querem: juros mais baixos, investimento estatal em infraestrutura, proteção alfandegária, BNDES a seu serviço e diplomacia empresarial e outras benesses, mas rejeitam a contratação de novos funcionários, reajuste para o funcionalismo, reajuste do salário mínimo, o gasto da previdência, etc. [...] querem um Estado enxuto para os trabalhadores e dadivoso para os empresários. $\mathrm{O}$ governo Lula procura manter alguns ganhos marginais para os trabalhadores, mas não é fácil encontrar o ponto de equilíbrio que evita defecções na frente política que ele representa (BOITO JR., 2012, p. 102).

Outra contradição dessa frente é identificada na oposição entre os interesses do agronegócio e os do movimento camponês. O governo Lula não poderia preservar a sua relação com o agronegócio em concomitância com a realização de uma efetiva reforma agrária. Como estratégia para não perder o apoio do movimento camponês, promoveu o aumento do crédito agrícola destinado à agricultura familiar, buscando contemplar os interesses dos camponeses com terra, sendo esta uma das bases do MST. Todavia, o governo Lula abandonou outra base desse movimento, que é composta pelo camponês pobre, sem-terra (Ibidem, pp. 103-104).

No contexto abordado, a grande burguesia interna reclamava a intervenção do Estado na economia como forma de atendimento de seus interesses frente a outras frações do bloco no poder, como o capital estrangeiro e a grande burguesia a ele associada, que se opõe ao projeto neodesenvolvimentista. Entretanto, a grande burguesia interna tinha dificuldade em aceitar as concessões que se faziam necessárias para manutenção da composição desta frente, mediante o atendimento de certas demandas dos setores assalariados, bem como do campesinato (BOITO JR., 2012). 
Os ardis do governo diante das classes trabalhadoras se expressaram por meio de uma dupla política estabelecida com esses setores. Ao mesmo tempo em que, para a consolidação e manobra da frente neodesenvolvimentista, o governo Lula cerrava fileiras com as frações organizadas das classes trabalhadoras, afastava-se destas na medida em que suas demandas assumiam uma posição de confronto com as classes dominantes que também compunham essa frente. Deste modo, buscar apoio nas classes populares desorganizadas e movidas por interesses difusos foi a estratégia encontrada para a atenuação dos conflitos da frente neodesenvolvimentista, de maneira que logrou-se, assim, o estabelecimento de uma relação do tipo populista desses setores populares com o governo Lula.

No desenrolar do primeiro mandato de Lula e no processo de sua reeleição, a manutenção desta frente, assim como o aprofundamento da política neodesenvolvimentista do governo, contou com o importante trunfo político referente ao maciço apoio das camadas mais pauperizadas do país, beneficiárias dos programas de transferência direta de renda e também de outras políticas sociais e econômicas do governo (IDEM, 2013, pp. 71-72). Essa fração das classes dominadas, cuja principal característica consiste em sua desorganização política enquanto classe social, foi mantida desorganizada por meio do fetiche do Estado protetor, que nesse caso particular, recebeu um substrato material por meio das políticas focalizadas que melhoraram suas condições de vida. Deste modo, este imenso contingente de pauperizados foi precipitado na cena política brasileira enquanto classe-apoio do projeto de desenvolvimento do governo em favorecimento tanto dos interesses políticos, quanto dos interesses econômicos da burguesia interna, tornando-se o principal sustentáculo eleitoral do governo Lula em 2006.

O conceito de classe-apoio é utilizado por Poulantzas (1977, pp. 238-239) na definição das classes que "apoiam” o Estado capitalista por acreditarem na noção de um Estado protetor que se coloca acima das lutas de classes e seja capaz de corresponder aos seus anseios. O autor exemplifica a ocorrência de classes-apoio no contexto histórico do fenômeno do bonapartismo na França do século XIX, ilustrando que o apoio conferido 
pelos camponeses parcelares ao governo de Luís Bonaparte se fundou, neste caso particular, unicamente num engodo ideológico pautado numa noção de compromisso do Estado com esses setores, sem que nenhuma medida política significativa fosse tomada com vistas à contemplação efetiva de seus interesses.

Conforme os fundamentos teóricos apresentados sobre a caracterização das classes-apoio, é possível afirmar que esse conceito é aplicável a governos cujas práticas se adequam à política populista. No populismo, as classes-apoio também são envoltas na noção ideológica de um Estado que atenda suas demandas, com a diferença de que parte desses anseios é realmente atendida, conquanto de maneira pertinente à manutenção da dominação e dos interesses políticos das classes dominantes. Neste ponto, destaca-se que a argumentação aqui apresentada a respeito da caracterização das classes populares durante o governo Lula enquanto classe-apoio do projeto neodesenvolvimentista se embasa em análises recentes (BOITO JR., 2013 e PINHEIRO, 2006) sobre a possibilidade do conceito de classe-apoio se estender também às classes trabalhadoras. Nessa operacionalização do conceito, ele não se baseia apenas numa relação ideológica entre o Estado e as classes populares, mas também em elementos concretos no que tange ao atendimento de interesses imediatos dessas classes dominadas.

Assim, questiona-se: quais seriam as características do populismo exercido pelo governo Lula? Considerando o debate exposto até aqui, é possível inferir que o referido governo tem pontos de contato e afastamento tanto com o populismo do século XX, quanto com o neopopulismo oriundo das práticas neoliberais, elementos que especificam sua particularidade.

A aproximação da política populista do governo Lula daquela exercida pelo "populismo clássico" consiste no fato de que este último foi indutor de um projeto político e econômico com vistas à autonomia do capitalismo nacional, responsável por fomentar a ascensão de uma burguesia industrial no país, integrando as classes dominadas de maneira subordinada nesse processo, através da implementação de direitos sociais de caráter constitucional (SAES, 1985). O governo Lula, por sua vez, 
também conduziu um projeto político e econômico responsável por favorecer uma fração da burguesia brasileira, incluindo subordinadamente frações das classes dominadas neste processo. Entretanto, as semelhanças param nesse ponto, pois a fração burguesa favorecida pelo governo em questão - a grande burguesia interna - tem sua margem de ação limitada à conjuntura mundial, não ousando refutar as determinações do capital estrangeiro. Além do mais, as políticas que favoreceram as classes dominadas corresponderam a medidas focalizadas que não alteraram a estrutura social brasileira, tampouco contribuíram para a ampliação dos direitos sociais de caráter universal.

O tipo de política populista desenvolvida pelo governo Lula também se aproxima da conceituação do neopopulismo apresentada por Saes $(2001)^{11}$, no que concerne à conjugação entre o estímulo à auto-exposição da personalidade individual como efeito típico da estrutura jurídico-política do Estado capitalista e o discurso ideológico desse governo. Esse discurso articulou elementos heterogêneos como a noção do "Lulinha paz e amor" - inventada por ele mesmo em sua campanha de 2002 - sob o intuito de atenuar sua imagem atrelada às lutas sindicais de outrora; e a imagem do trabalhador migrante que ascendeu à presidência da República-conhecedor dos reais problemas brasileiros - que se preocupa em oferecer o padrão classe média ao trabalhador comum. Contudo, as comparações entre o

\footnotetext{
${ }^{11}$ Saes (2001) destaca que a política da década de 90 surpreendeu os estudiosos que relacionavam o "populismo" enquanto uma política de "integração/controle das classes trabalhadoras" ao intervencionismo estatal. De acordo com o autor, no contexto do neoliberalismo, o discurso e a prática populista permaneceram, mas adaptaram-se a novos objetivos políticos que não figuram numa agenda desenvolvimentista. Diferentemente do populismo clássico, o neopopulismo tem o papel de desmantelar o Estado, que por sua vez é visto como o principal responsável pela desigualdade social devido à sua ineficiência. Assim, a proposta neoliberal, que opera como pano de fundo deste discurso, pode ganhar uma feição aparentemente progressista, como uma forma de combate redistributivo. O discurso neoliberal teve sua ampla aceitação popular devido ao "efeito social perverso" do período referente ao intervencionismo estatal. Para Saes, esta intervenção se fez em benefício quase que exclusivo da burguesia de Estado, que despontava nesta época, e da burguesia monopolista privada, não gerando benefícios expressivos para a classe trabalhadora. Deste modo, o apelo do neoliberalismo ao desmantelamento do Estado pode assumir ares progressistas, ao se pautar na retórica de um "combate redistributivo", embora a concretude dos fatos das gestões neoliberais desminta tal aspecto.
} 
tipo de populismo de Lula e o conceito de neopopulismo apresentado por Saes também se encerram nessas questões. Diferentemente da ideologia neopopulista em vigor no espraiamento do neoliberalismo no Brasil - que apresentava em seu discurso a insuficiência do Estado diante da desigualdade social brasileira - o discurso do governo Lula foi marcado pelo enaltecimento do papel ativo do Estado na retomada do crescimento endógeno em favor dos grupos econômicos nativos em consonância com uma efetiva política de distribuição de renda.

Deste modo, observa-se que o tipo de populismo identificado no governo Lula se encontra em um limiar entre a ideologia correspondente ao populismo de meados do século XX e o delineamento das políticas que vigoraram no populismo neoliberal. Esta constatação deriva do fato de que o governo em questão realizou mudanças na política econômica e social do país por meio de seu projeto neodesenvolvimentista, entretanto, de maneira atrelada ao modelo neoliberal periférico em vigor.

\section{CONSIDERAÇÕES FINAIS}

De acordo com o debate aqui realizado, é possível retirar algumas conclusões que, embora genéricas, levam a um melhor discernimento a respeito das particularidades políticas do governo Lula. No que se refere às políticas desenvolvidas para as classes dominadas, observa-se que houve melhorias concretas nas condições de vida destes setores sociais. Todavia, essas políticas não promoveram alterações de significativo impacto estrutural na formação social brasileira. As políticas de transferência direta de renda, embora tenham contribuído sobremaneira para a qualidade de vida da grande massa pauperizada brasileira, seguiram as determinações dos órgãos multilaterais. As demais políticas, como a ampliação do número de postos de trabalho, a promoção do acesso ao ensino superior privado e as políticas habitacionais, compatibilizaram-se com os interesses econômicos e políticos de diversos setores da grande burguesia interna.

Ademais, é possível identificar outro elemento da particularidade política do governo Lula referente à relação estabelecida entre frações da 
burguesia brasileira e os setores populares. A organização do bloco no poder no contexto destacado se deu mediante a aceitação da burguesia interna em ter seus objetivos operacionalizados por um governo cujo partido teve sua origem nos movimentos sociais e populares, fato que conduziu essa fração burguesa a uma forma particular de aliança com setores das classes trabalhadoras ${ }^{12}$. Essa aliança foi relativamente profícua em termos econômicos para as classes que a compuseram, pois refreou os efeitos deletérios do neoliberalismo extremado da década de 90. Contudo, contraditória em termos políticos, uma vez que a luta política entre classes diametralmente opostas é irreconciliável no âmbito do Estado capitalista, uma vez que a função precípua deste tipo de Estado consiste em organizar o bloco no poder em torno de seus interesses políticos com vistas à manutenção de sua hegemonia e desorganizar politicamente as classes dominadas.

Surge, então, outra questão que merece ser destacada. Partindo do pressuposto de que as classes dominadas também não se constituem de maneira monolítica ao serem compostas por diversas frações de classe principalmente nos países periféricos onde é grande nível de miserabilidade, como no caso do Brasil -, a incidência do processo de desorganização política, inerente à forma de Estado capitalista, também se deu de maneira particular durante o governo Lula.

Sem a intenção de realizar uma análise aprofundada, pode-se inferir que a incidência do processo de desorganização política ocorrida durante o governo Lula se deu de maneira distinta nas frações organizadas das classes dominadas. Alguns setores pertencentes a essa fração específica

\footnotetext{
${ }^{12}$ De acordo com Poulantzas (1977, p. 235-236) o conceito de aliança implica numa noção de unidade e contradição, sendo possível que uma aliança se concretize entre as classes ou frações que compõem o bloco no poder ou entre uma destas e outra classe ou fração externa às classes dominantes. A aliança, de acordo com o autor, é viável apenas num campo determinado da luta entre as classes sociais, sendo inexequível em todos os níveis. Desse modo, podemos afirmar que no intuito de combater os efeitos deletérios do neoliberalismo da década de 90 , a grande burguesia interna em sua luta contra a grande burguesia associada ao capital estrangeiro, aliou-se aos setores organizados das classes trabalhadoras, que também eram prejudicados sobremaneira pela política neoliberal. Entretanto, a luta política entre a burguesia interna e a classe trabalhadora organizada se manteve.
} 
das classes populares foram politicamente desorganizados por meio de uma ilusão concernente à possibilidade de partilharem o poder do Estado, mediante a integração institucional de alguns de seus quadros na burocracia estatal. Entretanto, outros setores dos movimentos sociais e populares souberam se distanciar desta noção revisionista a respeito do papel do Estado e mantiveram-se politicamente organizados e combativos sem se afastarem da luta política de classes.

Já no que concerne às frações das classes dominadas sem tradição de organização política, não é adequado afirmar que houve um processo de desorganização, mas é possível falar em mobilização eleitoral desses setores populares. Essa parcela da população, majoritária entre os trabalhadores brasileiros, foi a principal beneficiária das políticas sociais e econômicas implementadas pelo governo. Embora mantidas desorganizadas enquanto classe social, foram, em maior ou menor grau, "reorganizadas" pelas ações governamentais como classes-apoio do projeto político e econômico implementado. É inegável a funcionalidade política que essas camadas populares tiveram na implementação do neodesenvolvimentismo dos governos petistas.

Por meio da análise das particularidades conjunturais do governo Lula, é possível, portanto, afirmar que, no cumprimento da função geral do Estado, as políticas desenvolvidas, bem como a ideologia propalada, garantiram-lhe a característica de um governo populista neodesenvolvimentista, logo, diferente tanto do populismo clássico, quanto do neoliberal. O governo Lula realizou políticas que contemplaram os interesses imediatos de frações das classes trabalhadoras e da massa pauperizada e desorganizada, e, ao mesmo tempo, impulsionou a retomada do compromisso do Estado para com os grupos econômicos nativos. Assim, as políticas sociais e econômicas realizadas pelo referido governo, destinadas às classes populares, se articularam de maneira funcional ao projeto neodesenvolvimentista, o que beneficiou sobremaneira a grande burguesia interna, por meio da contemplação de seus interesses econômicos, de seus interesses políticos e da sua posição hegemônica no interior do bloco no poder brasileiro. 


\section{REFERÊNCIAS BIBLIOGRÁFICAS}

ALMEIDA, Wilson Mesquita de. Ampliação ao Acesso do Ensino Superior Privado Lucrativo Brasileiro: Um Estudo Sociológico Com Bolsistas do Prouni na Cidade de São Paulo. [Tese] São Paulo: Universidade Estadual de São Paulo, Programa de Pós-graduação em Sociologia, Departamento de Sociologia, 2012.

ARANTES, Pedro Fiore; FIX, Mariana. Minha Casa, Minha Vida', o pacote habitacional de Lula. In. Correiro da Cidadania, 30 de jun. 2009. Disponível em: <http://www.correiocidadania.com.br/index. php?...pcthabitacional310709...pacotehabitacio.> Acessado em: 25 de nov. 2016

ARAÚJO, José Prata. Um Retrato do Brasil: balanço do governo Lula. São Paulo: Editora Fundação Perseu Abramo, 2006.

BOITO JR., Armando. A burguesia no Governo Lula. In. Neoliberalismo y sectores dominantes. Tendencias globales y experiencias nacionales. Basualdo, Eduardo M.; Arceo, Enrique. CLACSO, Consejo Latinoamericano de Ciencias Sociales, Buenos Aires. Agosto 2006. pp. 237-263.

BOITO JR., Armando. Governo Lula: a nova burguesia nacional no poder. In. BOITO JR., A; GALVÃO, A. (org.). Política e classes sociais no Brasil dos anos 2000, São Paulo: Alameda Casa Editorial, 2012. pp. 67-104.

BOITO JR., Armando. O lulismo como bonapartismo: uma crítica às teses de André Singer. In. Revista Crítica Marxista, vol. 37, Campinas, 2013. pp. 171-81.

BOITO JR., Armando. Reforma e crise política no Brasil - Os conflitos de classe nos governos do PT. Editoras: Unicamp e Unesp: São Paulo, 2018. 
BRASIL. Minha Casa Minha Vida atinge 3,857 milhões de moradias. Disponível em: <http://www.brasil.gov.br/infraestrutura/2015/05/ minhacasaminhavidaatinge 3857 milhoesdemoradia $>$. Acessado em: 25 de nov. 2016.

CARVALHO, Cristina Helena .Almeida de. O Prouni no governo Lula e o Jogo Político em Torno do Acesso ao Ensino Superior. In. Educ. Soc., Campinas, vol. 27, n. 96 - Especial. pp. 979-1000, out. 2006.

CASALI Alípio Márcio Dias; MATTOS, Maria José Viana Marinho de. Análise de estudos e pesquisas sobre o sentido social do programa Universidade para Todos (PROUNI). In. Ensaio: Avaliação e Políticas Públicas em Educação. [online]. 2015, vol.23, n.88, 2015. pp. 681-716. Disponível em: http:/ /dx.doi.org/10.1590/S0104-40362015000300007. Acessado em: 20 mar. 2016.

DA REDAÇÃO. Consumo teve alta de $\mathrm{R} \$ 500$ bi na era Lula, dizestudo. Revista Exame. 10 out. 2010.Disponívelem:<http://exame.abril.com.br/ economia/consumotevealtader500binaeraluladizestudo540195/>. Acessado em: 22 nov. 2016

MERCADANTE, Aloísio. O Governo Lula e a construção de um Brasil mais justo. São Paulo: Editora Fundação Perseu Abramo, 2010.

MONTEIRO, Carlos Augusto. A dimensão da pobreza, da desnutrição e da fome no Brasil. In. Estudos Avançados, vol.17 n. 48, São Paulo Mai/Ago, 2003. pp. 7-20.

MORAIS, Lecio; SAAD-FILHO, Alfredo. Da economia política à política econômica: o novodesenvolvimentismo e o governo Lula. In. Revista de Economia Política, vol. 31, no 4 (124), outubro-dezembro, 2011. pp. 507-527.

NERI, Marcelo Côrtes; VAZ, Fabiano Monteiro.; SOUZA, Pedro Herculano Guimarães Ferreira de. Efeitos macroeconômicos do programa bolsa familia: uma análise comparativa das transferências sociais. In. Programa Bolsa Família: uma década de inclusão e cidadania. Brasília: Ipea, 2013. pp. 193-206. 
NOVELLI, José Marcos Nayme. A Questão da Continuidade da Política Macroeconômica entre o Governo Cardoso e Lula (1995-2006). In. Rev. Sociol. Polít., Curitiba, v. 18, n. 36. jun. 2010. pp. 227-240.

OLIVEIRA, Julio Cezar Pinheiro de. As dimensões coorporativas do Programa Minha Casa, Minha Vida, o dilema do limite entre uma a politica social e a política econômica. In. Anais XVI ENAPUR - Espaço, Planejamento e Insurgências. Belo Horizonte, 2015.

PINHEIRO, Jair. Uma cena decepcionante. In. Revista Lutas Sociais (PUCSP), vol. 15/16, São Paulo, 2006. pp. 149-161.

POCHMANN, Márcio. Nova classe média? O trabalho na base da pirâmide social brasileira. São Paulo: Boitempo, 2012.

POULANTZAS, Nicos. The Crisis Of Dictatorships. London: NLB, 1976.

POUlANTZAS, Nicos. Poder Politico e Classes Sociais. São Paulo: Martins Fontes, 1977.

ROMANHOLI, Alexandre J., O programa "Minha casa, minha vida": continuidades, inovações e retrocessos. In. Temas de Administração Pública. Vol. 4, n. 7. Araraquara, 2012. Disponível em: <http://seer.fclar. unesp.br/temasadm/article/view/6181>. Acessado em: 25 de nov. 2016. pp. 1-29

SAES, Décio. Classe Média e Sistema Politico no Brasil. São Paulo: T A. Queiroz Editor, 1985.

SAES, Décio. República do Capital - Capitalismo e processo politico no Brasil. São Paulo: Boitempo Editorial, 2001.

WRIGHT, Erik O. Classe, Crise e Estado. Rio de Janeiro: Zahar Editores, 1981.

Texto recebido em 15/02/2019 e aprovado em 03/08/2019 